\title{
Ocular Complications of Endocarditis
}

\author{
Ozlem Sahin \\ Middle East Technical University Health Sciences Department of Ophthalmology, \\ Ankara \\ Turkey
}

\section{Introduction}

Cardiac complications are the most common complications in patients with infective endocarditis, and they can be related to significant mortality and morbidity. (1) Extracardiac manifestations along with their historical descriptions such as splinter hemorrhages, emboli, Osler's nodes, Janeway and Bowman lesions of the eye, Roth's spots, patechiae and clubbing generally result from thromboemboli or septic emboli. (2) Inflammatory complications may occur as a result of septic emboli, and these include endogenous (metastatic) endophthalmitis, focal abscess, and vasculitis. (3) In this chapter we mainly focus on the endogenous endophthalmitis arising as a complication of infective endocarditis.

Endogenous (metastatic) endophthalmitis is an inflammatory condition of the intraocular structures including the aqueous, iris, lens, ciliary body, vitreous, choroid and retina. (4-6) It results from the hematogenous spread of organisms from a distant source of infection, most commonly infective endocarditis, gastrointestinal tract and urinary tract infections and wound infections. (7-9) Other sources of infection have included pharyngitis, pneumonia, septic arthritis and meningitis. $(10,11)$ Compared with endophthalmitis following trauma or surgery, endogenous endophthalmitis is relatively rare, accounting $2-8 \%$ of all reported endophthalmitis cases. (5) However, endogenous endophthalmitis carries with it the danger of bilateral infection in $15-25 \%$ of cases. $(6,12)$

\section{Epidemiology}

Endogenous endophthalmitis has been reported to occur at any age and no sexual predilection. (13) However, in the recent years the mean age of endogenous endophthalmitis has shifted to 65 years possibly because of the reduction in the incidence of rheumatic heart disease. (14)

The mean incidence of endogenous endophthalmitis was reported as1.8 cases/year, and $48.1 \%$ of patients presented were seen as outpatients. (15) Endogenous bacterial endophthalmitis is recognized as a major cause of visual loss with an associated high mortality rate. $(16,17)$ It is considered a diagnostic challenge in the early stages of the disease, with $16 \%$ to $63 \%$ of cases being initially misdiagnosed (18). In unilateral cases, the right eye is twice as likely to become infected as the left eye, probably because of the more proximal location and direct blood flow to the right carotid artery. (19) 


\section{Classification of endogenous endophthalmitis}

A classification system introduced by Greenwald et al. takes into consideration the affected areas of the globe and the associated visual prognosis. (20) It is divided as focal anterior or posterior, diffuse anterior or posterior and panophthalmitis. (20) Anterior focal endophthalmitis manifests as localized inflammatory nodules or plaques in the iris and /or ciliary body associated with iridocyclitis and minimal hypopyon. $(5,21)$ (Fig. 1) Intraocular pressure varies from normal to high. $(5,21)$ The anterior vitreous has no or minimal inflammation. $(5,21)$ The retina is normal. $(5,21)$ The prognosis in these cases is good. $(21)$ Anterior diffuse endophthalmitis is characterized by a more severe anterior segment inflammation associated with conjunctival chemosis, marked anterior chamber reaction with fibrin clots and significant hypopyon that hampers the view of retina. $(5,21)$ (Fig. 2)

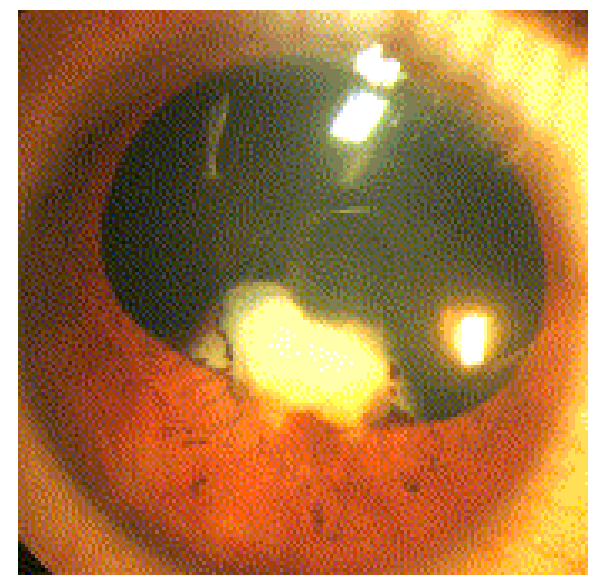

Fig. 1. Anterior focal endophthalmitis presented with an inflammatory nodule in the iris extending from the ciliary body

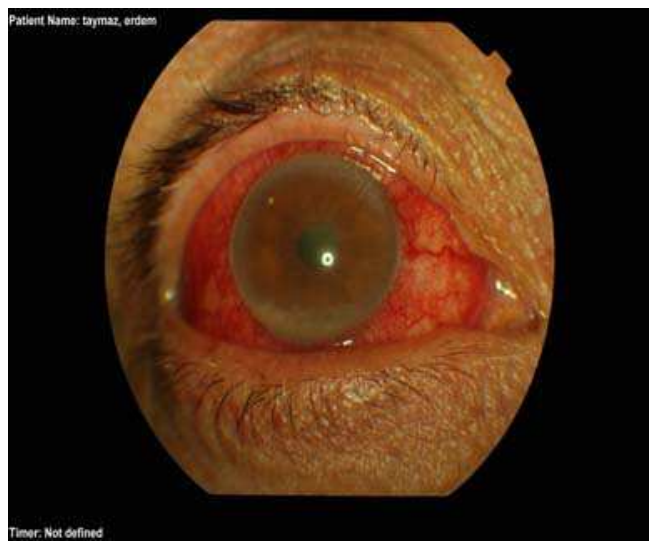

Fig. 2. Anterior diffuse endophthalmitis with a more severe anterior segment inflammation associated with conjunctival chemosis, marked anterior chamber reaction with fibrin clots and significant hypopyon 


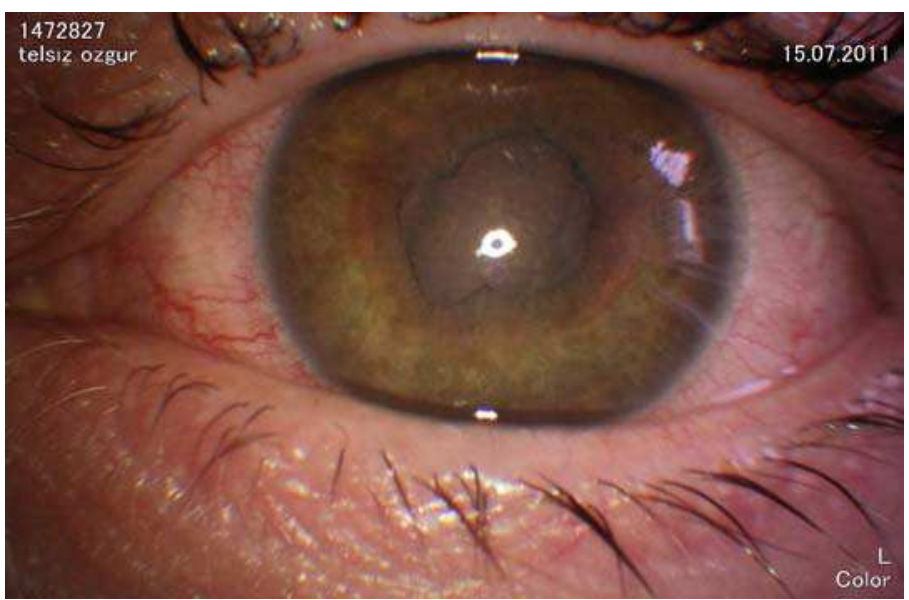

Fig. 3. Anterior diffuse endophthalmitis with posterior synechia and corneal haze

Intraocular pressure is typically elevated. (22) Corneal opacification may occur. (22) (Fig. 3) It is an ocular emergency and if not promptly and adequately treated the infection can spread to the entire eye. (22) The visual prognosis is excellent with aggressive and appropriate treatment. Blindness usually results from delay in treatment. (22) Posterior focal endophthalmitis manifests as white-yellowish retinal or choroidal lesions associated with retinal hemorrhages and vitreous cells and/or debris. (23) (Fig. 4) Infections caused by Gram-positive organisms may show multifocal lesions. (23) However, Gram-negative infections usually cause a single large choroidal abscess involving the posterior pole. $(24,25)$ (Fig. 5) The anterior chamber reaction is usually mild with or without keratic precipitates. (23) (Fig. 6) The intraocular pressure varies from low to normal. (23) Posterior diffuse endophthalmitis may present as multiple whitish lesions located inside the vessels or in the

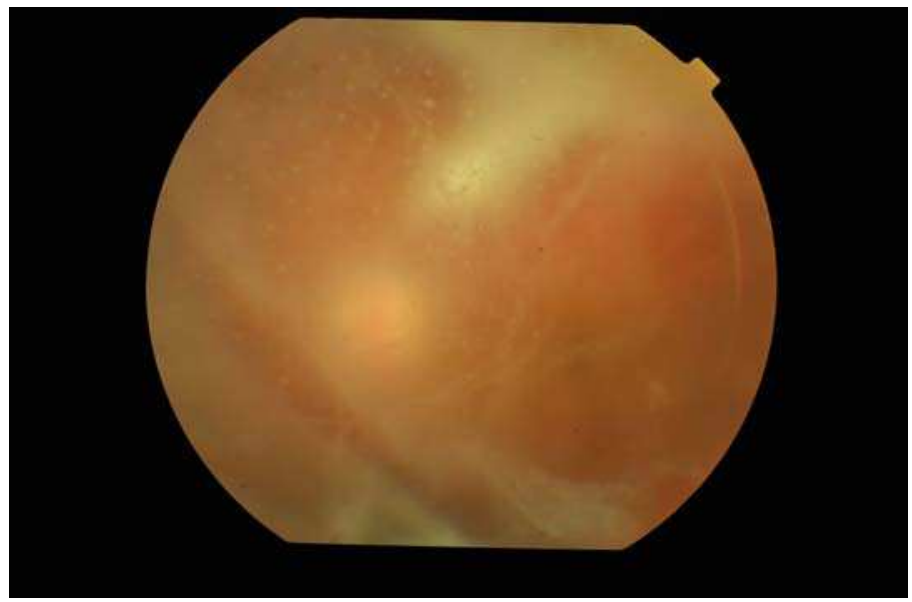

Fig. 4. Posterior focal endophthalmitis manifested as white-yellowish retinal or choroidal lesions associated with vitreous cells and/or debris 


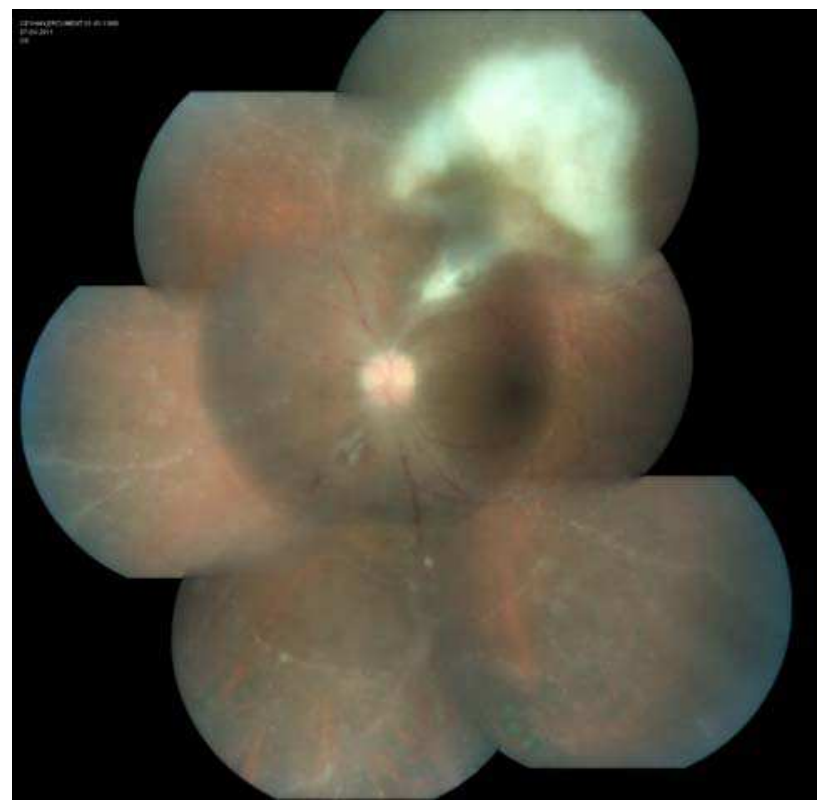

Fig. 5. A single large choroidal abscess involving the posterior pole

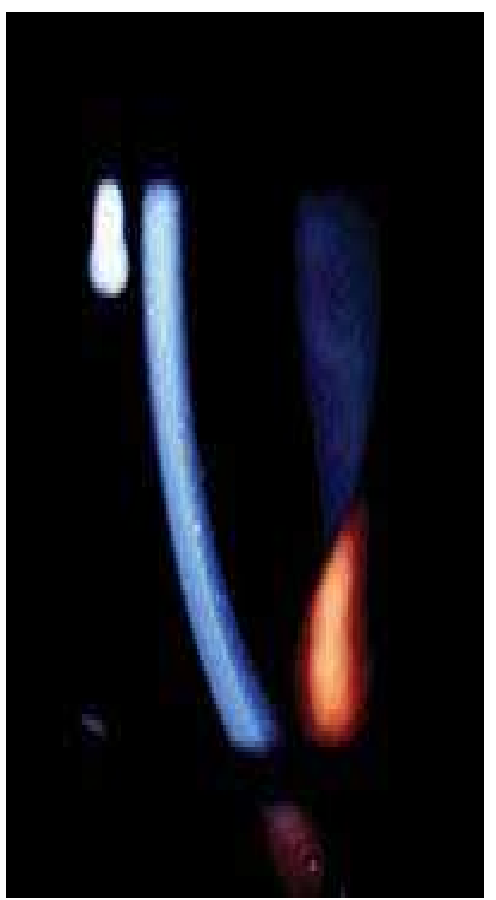

Fig. 6. Mild anterior chamber reaction with keratic precipitates 
retina with perivascular hemorrhages in the early stages of the disease. (26) As the infection progresses, the retina becomes necrotic, and vitreous abscess frequently occur. (26) (Fig. 7) The anterior segment is also involved with forward spread of the infection and hypopyon is formed as the disease progresses. (26) (Fig. 8) The intraocular pressure is low. (26) The poor visual prognosis is most likely due to retinal ischemia as a result of occlusion of central retinal artery by a septic embolus. (26) Panophthalmitis is inflammation of all coats of the eye including intraocular structures. (27-29) It presents with marked lid edema, proptosis and limitation of ocular movements. (28) (Fig. 9) All details of anterior as well as posterior chamber are lost because of the prominent hypopyon. (29) (Fig. 10) Typically the intraocular pressure is high. (29)It is a disastrous and rapidly developing infection that destroys the globe and invades the orbit, resulting in blindness, phthisis or enucleation. $(28,29)$ Depending of the virulence of pathogen, progression of panophthalmitis may be life threatening. (28)

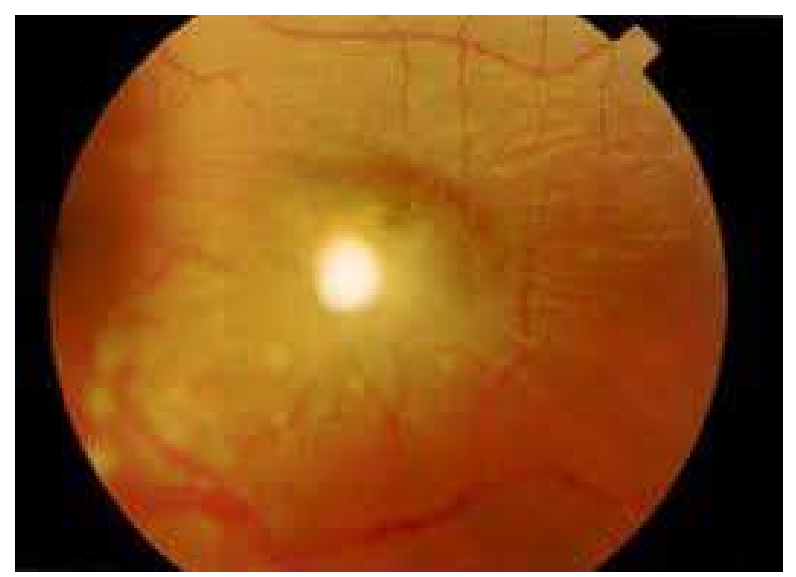

Fig. 7. Necrotic / hemorrhagic retina with vitreous abscess

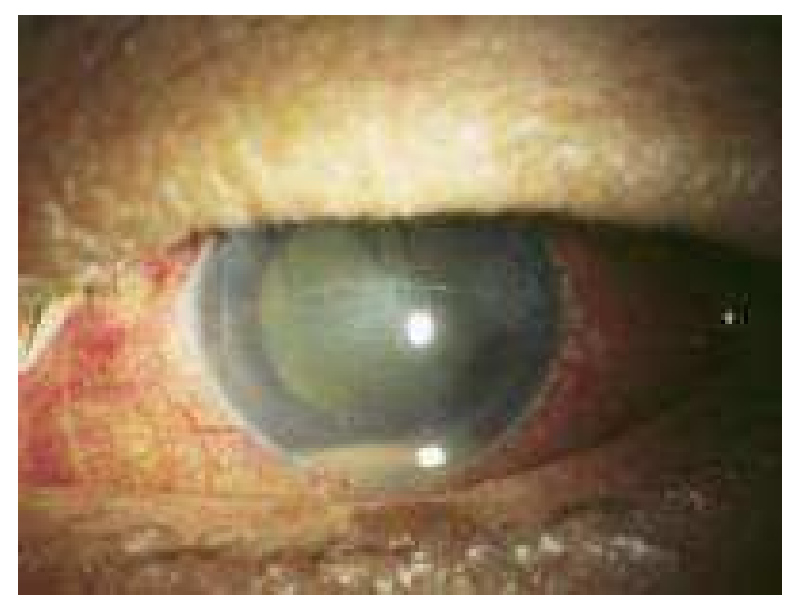

Fig. 8. Forward spread of infection with hypopyon formation 


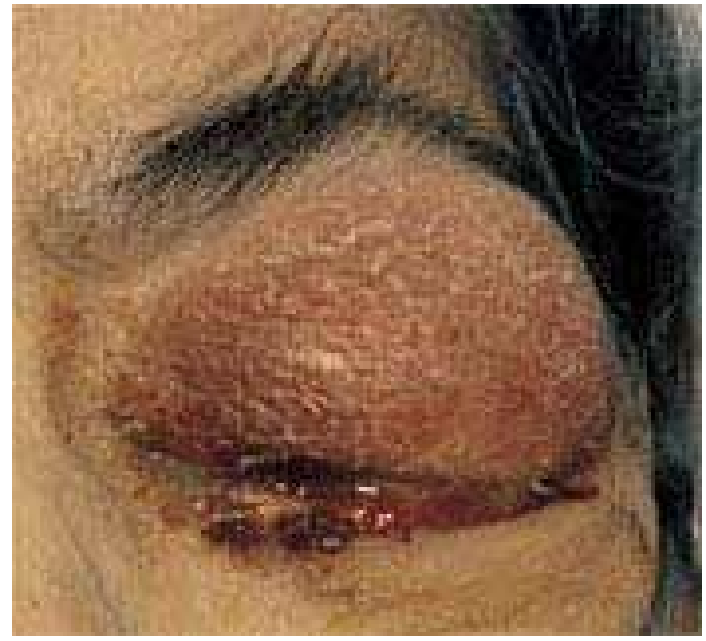

Fig. 9. Panophthalmitis with marked lid edema and proptosis

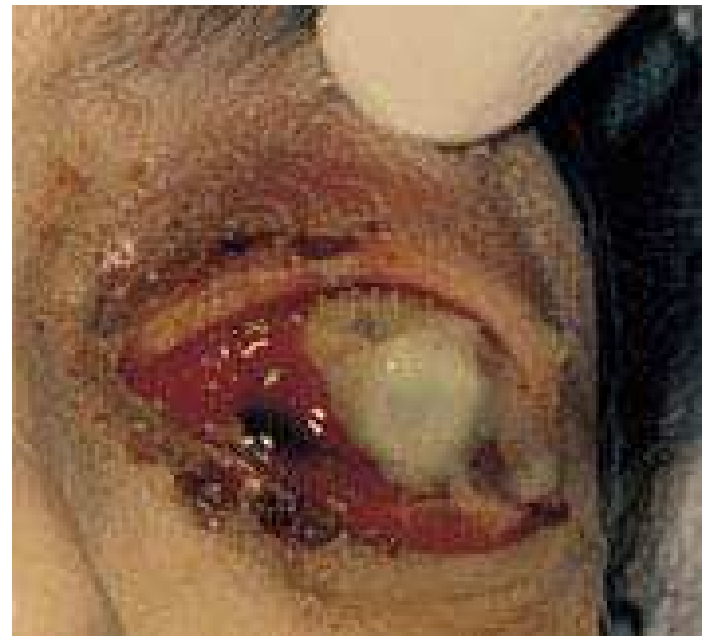

Fig. 10. Severe panophthalmitis with loss of the details of anterior and posterior segments of the eye

\section{Pathogenesis}

In endogenous endophthalmitis the microorganisms enter into the uveal tract or retinal circulation as scattered organisms or in a bolus, and lodge in small capillaries. $(30,31)$ To invade ocular tissues and produce infection the organisms must cross the blood-ocular barrier either by direct invasion (septic emboli) or by changes in vascular endothelium caused by substrates released during infection. (30) They establish a septic focus that can develop in the retina prior to breaking into the vitreous. (30) The infectious embolus is usually in proximity to the retinal vessels. (30) If a large septic embolus pass through the 
central retinal artery and disseminates throughout the retina, retinal necrosis and ischemia may occur. (30) This allows the microorganisms to quickly invade the vitreous and further the anterior segment, causing inflammation of intraocular tissues (panuveitis) that may be mixed-up a non-infectious inflammatory disease. (31) Similarly, in cases of fungal endophthalmitis a localized inflammatory reaction surrounding a small nidus of fungi forms in the inner choroid, breaks through Bruch's membrane into the retina forming a microabscess and spreads into the vitreous cavity. (31) It is a destructive process that has a poor visual prognosis that the visual loss rate reaches up to $37.5 \%$. (30) The final visual outcome in patients with endogenous bacterial endophthalmitis in the recent 12 years has not differed significantly from five decades ago. (31) Under normal circumstances, the blood-ocular barrier provides a natural resistance against invading organisms. (30) Destruction of intraocular tissues may be due to direct invasion of the organism and/or from inflammatory mediators of the immune system. $(30,31)$ In any type of endophthalmitis, bacteria are introduced into the intraocular environment, encountering a site of immunological inactivity. (30) The intraocular environment is termed an "immune privileged site", devoid of inflammatory mediators and cells present that would otherwise fight infection. (32) The blood-ocular barrier facilitates maintenance of a sterile environment in the interior of the eye contributing to the immune privileged site. (32) In this environment initial immune responses that would typically handle infection are delayed or absent, providing an optimum growth medium for the organisms that reach the area. (32) Eventually, organisms are recognized and inflammation initiates in an effort to handle the infection. (30) The extent of inflammation in the eye is during endophthalmitis has been shown to be organism dependent. $(30,31)$ The course of endophthalmitis, treatment effectiveness and visual outcome can be unpredictable. (33) Clinical presentation of the disease depends, in part, on the relative virulence of the infecting pathogen, the mechanism of introduction into the eye and how quickly treatment is initiated. (33) Other factors that affect the outcome of infection include the patients' age, how vulnerable the infecting agent is to antibiotic therapy and the anatomic condition of the eye during infection. (33) Clinical studies have reported that increased time between infection and treatment is associated with a worse visual outcome. $(19,34)$ Endophthalmitis may be as subtle as white nodules on the lens capsule, iris, retina, or choroid. (35) It can also be as ubiquitous as inflammation of all the ocular tissues, leading to a globe full of purulent exudate. (36) In addition, inflammation can spread to involve the orbital soft tissue. (37)

\section{Mortality/morbidity}

Decreased vision and permanent loss of vision are common complications of endophthalmitis. $(33,34)$ Patients may require enucleation to eradicate a blind and painful eye. (38) Mortality is related to the patient's comorbidities and the underlying medical problem, especially when considering the etiology of hematogenous spread in endogenous infections. $(39,40)$

\section{Clinical presentations}

Bacterial endophthalmitis usually presents acutely with pain, redness, lid swelling, and decreased visual acuity. $(11,16,22)$ Specific signs have been described which may suggest a specific infecting organism. For example, Bacillus infections characteristically demonstrate 
chocolate brown anterior chamber exudates with a ring-shaped white corneal infiltrate. (41) Serratia infections may be associated with a pink or dark hypopyon. $(42,43)$ An eye with Klebsiella or Group B Streptoccoccus endogenous endophthalmitis often has a pupillary hypopyon. $(44,45)$ The hypopyon associated with Group B Streptococcus often does not organize and shifts to occupy the most dependent portion of the anterior chamber. This has been termed a "sliding hypopyon". (46) Fungal endophthalmitis may present with an indolent course over days to weeks. (47) Symptoms are often blurred vision, pain and decreased visual acuity. (47) Individuals with candidal infection may present with high fever, followed several days later by ocular symptoms. (48) Persistent fever of unknown origin may be associated with an occult retinochoroidal fungal infiltrate. (48) A characteristic sign of endogenous Candida endophthalmitis is a creamy, white, wellcircumscribed lesion, involving the retina and choroid in the posterior pole. (48) Aspergillus endogenous endophthalmitis, although less common, is frequently a more fulminant disease. (40) Nearly all patients have anterior chamber cells and keratic precipitates. (40) The inflammation may result in hypopyon, pupillary membrane, rubeosis iridis, and an anterior chamber inflammatory mass. (40) Posteriorly, chorioretinitis may appear as fluffy yellowwhite elevated chorioretinal opacities. (49) Gravitational layering of the inflammatory cells may produce a subhyaloid or subretinal "hypopyon" especially since subretinal and subretinal pigment epithelial infection tends to occur with Aspergillus. (49) Retinal detachment mat complicate the infection. (40) Retinal haemorrhages and perivasculitis may be present. (40) Ultimately full thickness retinal necrosis may occur. (40) The earlier signs of endogenous endophthalmitis include Roth's spot (round, white retinal spots surrounded by hemorrhage) (Fig. 11), hemorrhagic spots in the conjunctiva, superficial or profound retinal hemorrhage, and retinal periphlebitis. (20-22) The occlusion of small arterioles may produce cotton-wool spots, or if the larger vessels are involved, branch retinal or central retinal artery obstruction. (20-22) Slit-lamp examination reveales ciliary injection, keratic precipitates $(\mathrm{KP})$, mild to moderate cells and flare in the anterior chamber or severe iritis with hypopyon formation and fibrin precipitates. $(21,22)$ Ophthalmoscopy shows infiltrations of the retina and vitreous, retinal vasculitis and retinal hemorrhage or dense vitreous opacities progressing to white mass obstructing fundus view. $(26,27)$ If the fundus

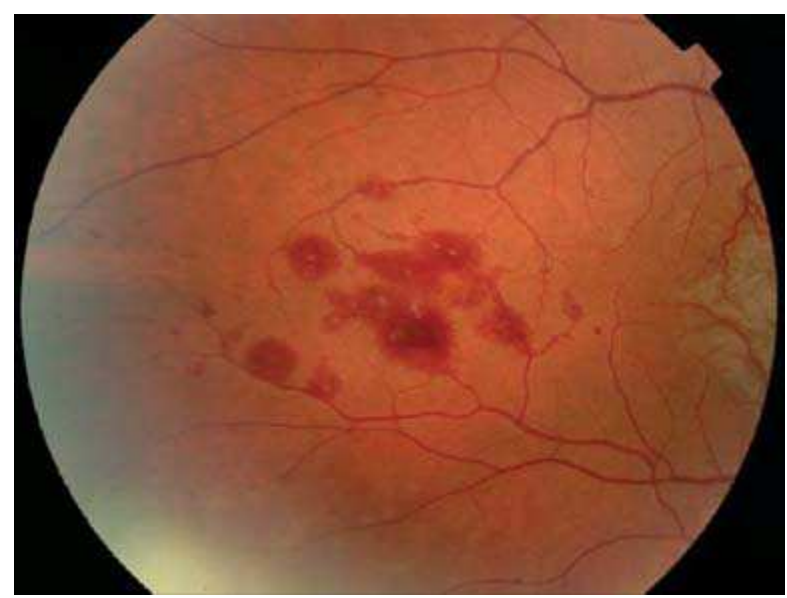

Fig. 11. Roth Spots characterized by round, white retinal spots surrounded by hemorrhage 
view is obscured, imaging with optical coherence tomography, ocular ultrasonography, electroretinogram tests are useful in displaying the extent of vitreous involvement, choroidal abscesses, retinal detachment and scleral thickening. $(16,18,22)$ Computed tomography scans allow high resolution orbital imaging in cases of suspected panophthalmitis to detect abscess formation or confirm the presence of contiguous orbital involvement. (37)

\section{Causes}

Individuals at risk for developing endogenous endophthalmitis usually have comorbidities that predispose them to infection. These include conditions like diabetes mellitus, chronic renal failure, cardiac valvular disorders, prosthetic heart valves, systemic lupus erythematosus, AIDS, leukemia, gastrointestinal malignancies, neutropenia, lymphoma, alcoholic hepatitis, intravenous drug abuse, and bone marrow transplantation. (50,51) Sources of endophthalmitis include most commonly endocarditis followed by urinary tract infection, wound infection and meningitis. (4) Additionally, pharyngitis, pulmonary infection, septic arthritis, pyelonephritis and intraabdominal abscess have also been implicated as sources of infection. (10) About 25\% of the cases are bilateral and usually caused by Meningococcus, E.coli and Klebsiella species. $(52,53)$ The most common cause in two-thirds of the infections is Gram-positive bacteria. $(31,33)$ Although the most common agent was S.aureus (25\% of patients), the most common group was streptococcus (32\%). $(31,33)$ Endogenous endophthalmitis in adults caused by group B Streptococcus has been reported rarely and is almost exclusively related to infective endocarditis. $(7,54)$ Gramnegative organisms cause $32-37 \%$ of all endogenous endophthalmitis cases and typically have poor visual outcomes because these infections are difficult to treat. $(5,55,56)$ The low prevalence of Gram-negative bacteria amongst the causative organisms of both infective endocarditis and endogenous endophthalmitis might be related to the absence of an outer capsule, which makes them sensitive to complement mediated lysis and other humoral innate immune defenses, and the lack of surface proteins that specifically bind host matrix molecules and prosthetic material. (57) Moreover, a much higher inoculums of Gramnegative than Gram-positive organisms is required to induce infective endocarditis in laboratory animals. (57) Although aggressive therapy was given, the visual prognosis for all these patients was poor. $(56,57)$ E. coli emphysematous endophthalmitis is a very rare and severe variety of E. coli endophthalmitis. $(58,59)$ The mechanism of emphysematous endophthalmitis has been postulated that a high concentration of glucose in the eye tissue may provide a substrate that bacteria can ferment to produce carbondioxide and hydrogen. (58) A computerized tomography scan of the orbits demonstrate gas bubble in the eye globe indicating emphysematous endophthalmitis. (59) Extra-intestinal pathogenic E.coli (ExPEC) are able to colonize tissue outside the gastrointestinal tract and contain a variety of virulence factors that may enable the pathogens to invade and induce infections in the cardiac endothelia. $(57,60)$ These cases are further complicated by spondylodiscitis and bilateral endophthalmitis. (60) Endogenous endophthalmitis is usually associated with Gram-negative bacteria, most commonly Klebsiella pneumonia (77.4\%) among the East Asian population. $(6,61,62)$ The patients at highest risk are diabetic patients with hepatobiliary infections. $(6,61)$ Klebsiella pneumonia endogenous endophthalmitis is a severe but potentially subclinical disease. (62) Early diagnosis requires a high index of suspicion and recognition of risk factors including Asian ancestry and other sources of systemic infection including most 
commonly liver abscess. $(6,61)$ In contrast, in the Caucasian population, Gram-positive cocci including Staphylococcus aureus, Streptococcus pneumonia and other streptococcal species are the most common causes of bacterial endogenous endophthalmitis. $(31,33)$ Septic metastasis to the iris is a rare manifestation of endogenous endophthalmitis presented with acute painful red eye, hypopyon and iris abscess that might be caused by S.aureus. (63) Subacute bacterial endocarditis caused by viridians streptococci is characterized by a lingering start of the disease with high temperature of unknown origin and an unspecific feeling of illness. $(64,65)$ The ophthalmological findings can manifest itself before the diagnosis of the underlying disease is made. (65) Complications such as blindness after fulminant endophthalmitis and death can be avoided through quick diagnosis and treatment. $(64,65)$ Group B Streptococcus endogenous endophthalmitis is a devastating condition with poor visual prognosis despite therapy. $(66,67)$ It is a rare condition that 17 cases have been reported since 1985. (7) Group B Streptococcus endogenous endophthalmitis was found to arise from hematogenous spread from endocarditis at a rate of $33.3 \%$. (7) Increasing incidence of invasive Group B Streptococcus infection with its varying manifestations including metastatic endophthalmitis has been reported recently in adults with predisposing illnesses. $(54,68)$ Streptococcus anginosus is a member of Streptococcus milleri group and is a commensal found in the mouth, nasopharnyx, throat and sinuses. (69) It is associated with infective endocarditis with a longer than average duration of evolution before diagnosis. (70) S. anginosus should also be considered in the differential diagnosis of a slowly progressive endogenous endophthalmitis when fungal infection is considered likely. (70) Bartonella henselae and Tropheryma whipplei are rare pathogens in humans and were recently recognized as important causative agents of culture-negative endocarditis that the bacteria are indentified by polymerase chain reaction analysis. $(71,72)$ Exposure to cats is an important risk factor for B.henselae which is the causative agent of cat scratch disease characterized by persistent regional lymhadenopathy. (73) B. henselae is responsible for endocarditis in patients with valvular diseases, and may induce retinitis. (73) Whipple's disease is characterized by wide range of clinical manifestations involving diarrhea, weight loss, night sweats, arthritis, vitritis retinitis and papillitis. (74)

Fungal organisms can occur in up to $50 \%$ of all cases of endogenous endophthalmitis. (57) Candida albicans is by far the most frequent cause (75-80\% of fungal cases). (57) Since 1980, candidal infections reported in intravenous drug users have increased. (57) The number of people at risk may be increasing because of the spread of AIDS, more frequent use of immunosuppressive agents, and more invasive procedures. $(57,75)$ The classic finding of Candida endophthalmitis is white chorioretinal infiltrates with fluffy white vitreous opacities described as "string of pearls" appearance. $(76,77)$ The chorioretinitis may progress and satellite lesions may develop adjacent to the primary lesions. (77) Occasionally anterior uveitis, scleritis and panophthalmitis may also occur. (77) Aspergillus endogenous endophthalmitis, although less common, is frequently a more fulminent disease. (76) It has a predilection for the postequatorial fundus. (78) A confluent yellowish infiltrate is usually seen in the macula beginning in the choroid or subretinal space. (78) Histologically, the retinal and choroidal lesions are angiocentric. (76) Unlike candida endophthalmitis, in which the vitreous is the primary focus of infection, aspergillus endophthalmitis is marked by retinal and choroidal vessel invasion and subretinal pigment epithelial and subretinal infection. (76) The lesions can progress to retinal vascular occlusion and full-thickness retinal necrosis. (78) Intraretinal hemorrhages usually occur. (78) Eventually the infection 
spreads into the vitreous, producing dense vitritis, and into the anterior segment, producing varying degrees of cell/flare and hypopyon in the anterior chamber. $(76,78)$ The macular lesions heal to form a central atrophic scar. (78) Endogenous cryptococcal endophthalmitis has nonspecific ocular inflammatory signs including intraretinal hemorrhage, vascular sheathing, yellow-white chorioretinal mass or scarlike lesion. $(79,80)$ Retinal detachment may complicate the infection. (79) The infection is usually misdiagnosed as sterile uveitis. (79) Suspicion of infection should be greater in the presence of a yellow or white chorioretinal abscess. $(79,80)$ Coccidioidal endophthalmitis is an uncommon presentation in patients with disseminated disease. (81) Usually a severe granulomatous iridocyclitis characterized by mutton- fat keratic precipitates is present. (81) Multifocal choroiditis, typified by several, scattered, discrete yellow-white lesions measuring less than the disc diameter in size, is observed. (81) Occasionally, vascular sheathing, vitreous haze, serous retinal detachment and retinal hemorrhage may also be seen. (81) Less commonly, Histoplasma capsulatum and other dimorphic fungi have been implicated in endogenous endophthalmitis. (57) Endogenous histoplasmic endophthalmitis has been reported in several patients with disseminated systemic histoplasmosis. (82) The ocular infection may result in a granulomatous anterior uveitis. (82) Vitritis may be mild to severe. (82) The classic fundus lesion is a cream-colored or gray-white chorioretinal infiltrate, often surrounded by hemorrhage. (82) There may be associated retinal pigment epithelial alteration, indicating partial spontaneous healing. (82) The lesions may be solitary or multiple can range from less than a disc diameter to several disc diameters. (83) Histoplasmic optic neuritis has also been reported in association with the chorioretinitis. (83) The ocular findings are not specific for histoplasmic endophthalmitis, and the diagnosis should be suspected in any immunosuppressed patient living in an area endemic for histoplasmosis. (83) Rare causes of endogenous fungal endophthalmitis include Fusarium species, Mucormycosis, Paecilomyces species, Pencillium species, Bipolaris hawaiiensis, and Trichosporon beigelii. $(84,85)$ Endophthalmitis due to systemic fungaemia is less commonly reported in East Asian countries. (57)

\section{Diagnosis}

The high incidence of misdiagnosis of endogenous endophthalmitis ranging from conjunctivitis, acute glaucoma or other ocular conditions should alert the ophthalmologist to make a correct diagnosis of this insidious entity. The possibility of endogenous endophthalmitis should be considered in any patient who manifests a pronounced anterior reaction that is refractory to steroid treatment. The appropriate diagnosis is necessary to start the appropriate treatment and influence dramatically the visual outcome as well as reduce the incidence of systemic complications, sometime fatal. Therefore the crucial point is diagnostic suspicion. The diagnostic algorithm should include accurate ocular and systemic history, investigation of risk factors, search source of infection, fluorescein angiography, (Fig. 12) B/A scan ocular ultrasonography, (Fig. 13) and computerized tomography of the orbit (Fig. 14) to exclude posterior involvement, and during the followup to monitor the adequacy of treatment, anterior aqueous tap, vitreous tap or vitrectomy, gram stain and culture of ocular and non-ocular fluids including blood, urine, cerebrospinal fluid. Organisms are cultured from ocular fluid in 36-73\% of cases. (50) In many cases, prior treatment for systemic infection with intravenous antibiotics had already been instituted and this would reduce the culture positive rate from ocular fluids. A second factor resulting 


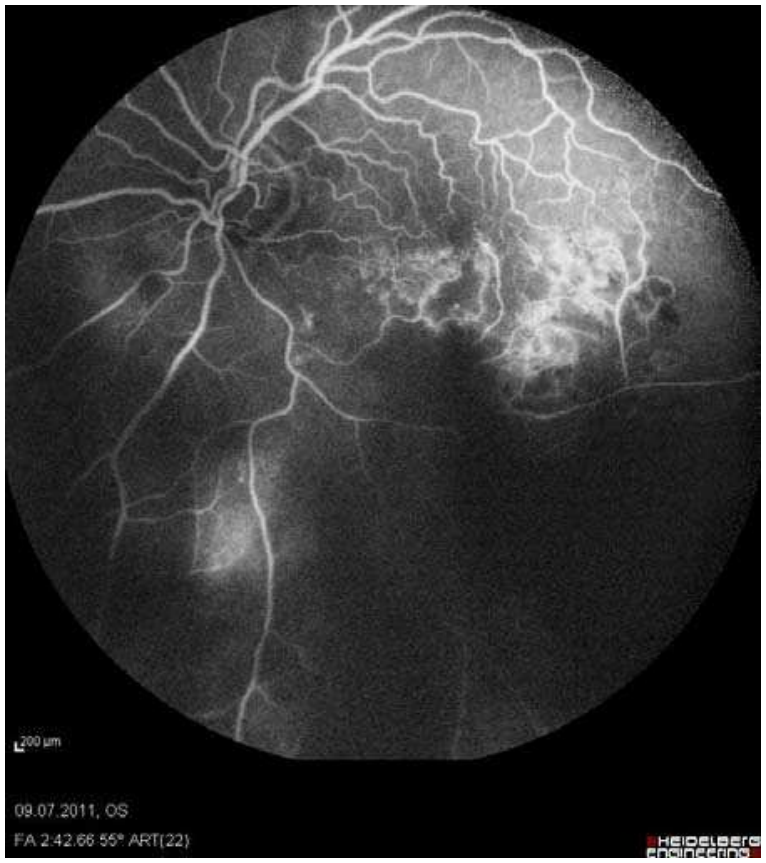

Fig. 12. Fluorescein angiography showing the areas of vascular leakage (hyperfluorescent) and the areas of retinal hemorrhage (hypofluorescent)

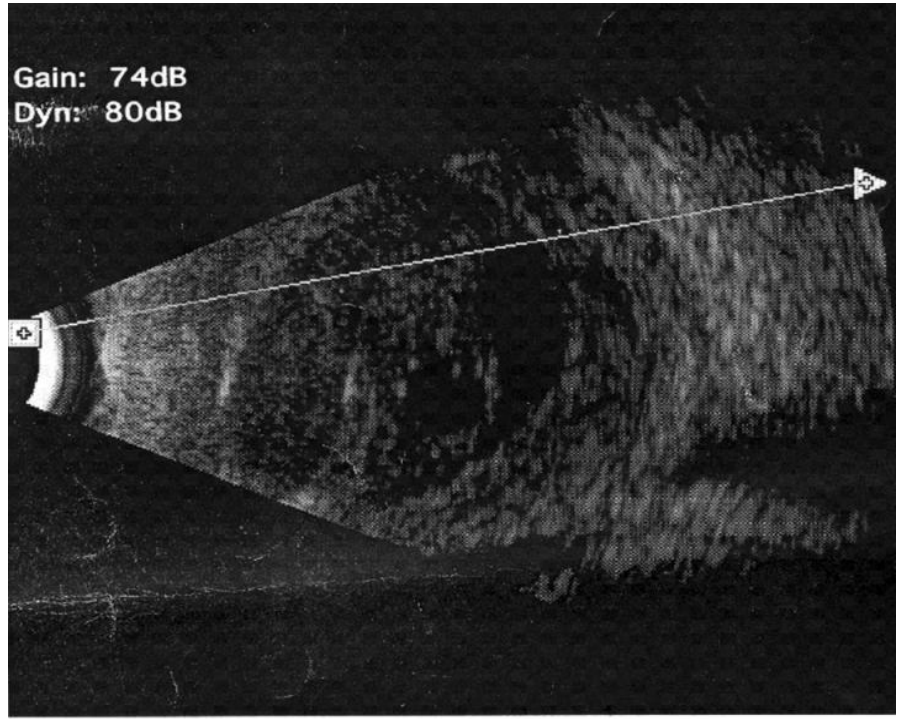

$33.71 \mathrm{~mm}$

Fig. 13. B-Scan ultrasonography of the eye showing scleral thickening and dense vitreous inflammatory opacifications 
in a negative culture is sampling from an inappropriate compartment within the eye. Both aqueous and vitreous cultures should be obtained unless the organism has been identified from a non-ocular source. Beyond an initial diagnostic aqueous and vitreous tap, a pars plana vitrectomy can provide additional material for culture. It should be inoculated in blood agar, chocolate agar, brain-heart infusion broth/agar, thioglycollate broth and Sabouraud agar. (50) A specimen sent for Gram stain may allow provisional categorization of the organism. Polymerase chain reaction (PCR) may allow rapid identification of organism with high sensitivity, but specificity may be a problem and facilitates for this test are not widely available. (50) In comparison with bacterial endogenous endophthalmitis, those case caused by fungi rarely have a positive blood culture. (86) Systemic fungaemia is either transient or not recognized prior to eye infection. (47) On the other hand, screening of several series of patients with candidaemia has not revealed any cases of endophthalmitis. (47) The benefit of screening lucid, asymptomatic patients thus remains doubtful at this point of time. $(47,50)$ However, vitreous cultures will often reveal the offending organisms in these cases. (86) Vitrectomy samples are more sensitive for fungal cultures than vitreous needle biopsies. (86) The cultures must be kept at the laboratory for at least 4-6 weeks to ensure that slow-growing or fastidious fungal organisms are not missed. (86) PCR is also used as a diagnostic tool for fungal endophthalmitis. $(87,88)$ The main advantage of PCR over conventional fungal cultures are the higher sensitivity and the rapid results. $(87,88)$ Although PCR does not replace conventional mycologic methods, it helps to make an early differentiation between bacterial endophthalmitis and fungal endophthalmitis. (88) Candida species grow well on Sabouraud media without cycloheximide. (89) The colonies are white and pasty. (89) Aspergilli species are observed best with Grocott Methenamine Silver (GMS) or Periodic acid-Schiff (PAS) stains. (90) Aspergilli cultures are initially flat, white and filamentous. (90) Within 48 hours, conidia are produced with a concomitant change in

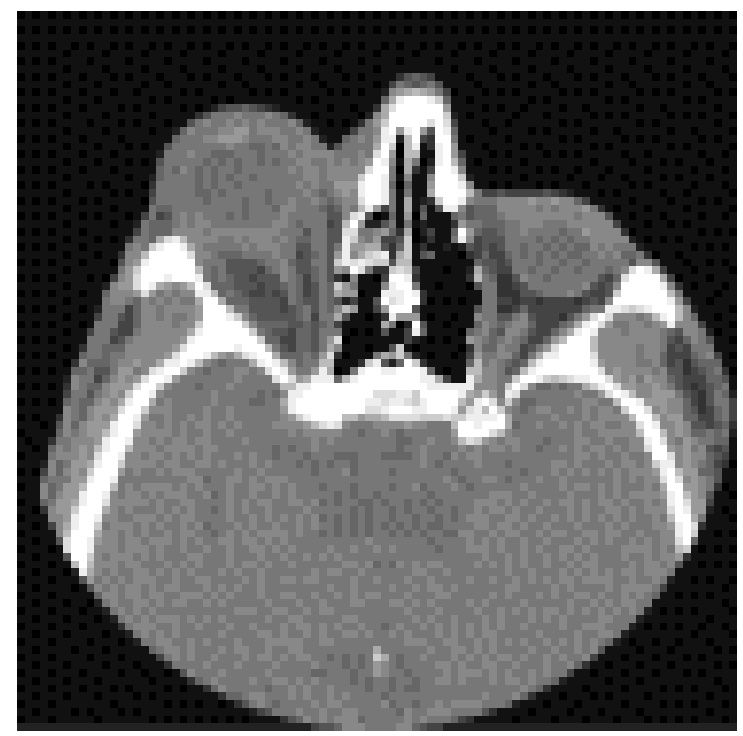

Fig. 14. Orbital tomography showing proptosis, extraocular muscle enlargement, soft tissue swelling and retrobulbar fat stranding of the left eye 
pigmentation. (90) Cryptococci also grow well in Sabouraud agar. (91) It may be identified by India ink. (91) Coccidioidomycosis can be diagnosed using a $10 \% \mathrm{KOH}$ mount and identifying endospores that contain spherules. (92)

Apart from microbiological investigation, other tests may be required according to the clinical picture. These would include complete blood cell count with differential, erythrocyte sedimentation rate, blood urea nitrogen and creatinine.

\subsection{Differential diagnosis}

Endogenous endophthalmitis should always be considered early in the differential diagnosis of anterior uveitis. (87) The common causes of anterior uveitis must be excluded by the usual serological tests. (87) Glaucoma, CMV retinitis, toxoplasma chorioretinitis, primary intraocular lymphoma, syphilitic chorioretinitis, autoimmune causes, malignancies, masquerade, metastatic tumors, and other infectious diseases should also be ruled out. (93) Rarely, cavernous sinus thrombosis, corneal abrasion, corneal laceration, corneal ulceration and ulcerative keratitis, globe rupture, herpes zoster ophthalmicus and vitreous hemorrhage are included in the differential diagnosis. $(78,94)$

\section{Medical treatment}

\subsection{Systemic therapy}

Prompt administration of antibiotic therapy is the key in the acute management of endogenous endophthalmitis. Systemic antibiotics also treat distant foci of infection and prevent continued bacteremia, thereby reducing the chances of invasion of the unaffected eye. Prolonged intravenous therapy is usually required for 2-4 weeks, until it is certain that the systemic infection is eradicated. (33) Empiric broad-spectrum antibiotic therapy with vancomycin and aminoglycoside or a third-generation cephalosporin is recommended at the highest theurapeutic doses. $(33,52)$ Gentamycine has the coverage of gram-negative organisms including Pseudomonas aeruginosa. $(25,44)$ It is the first choice aminoglycoside for systemic gram-negative coverage. $(25,44)$ It has bacteriocidal activity by binding to $30 \mathrm{~S}$ ribosomal subunit and inhibiting protein synthesis. (44) Ceftazidime is the third-generation cephalosporin with broad gram-negative coverage but decreased efficacy to gram-positive organisms. $(95,96)$ It binds to one or more of the penicillin-binding proteins and prevent cell wall synthesis inhibiting bacterial growth. (95) Ceftriaxone is another third-generation cephalosporin is active against the resistant gram-negative organisms. (12) For Grampositive cover, intravenous vancomycin is warranted in the view of the potential severity of the disease and consequences. $(95,96)$ Good Gram-negative coverage is provided by thirdgeneration cephalosporins, ciprofloxacin and aminoglycosides. $(25,44)$ Although intravenous antibiotics can reach therapeutic concentrations in affected eyes, the use of systemic antibiotics that have good intraocular penetration and bioavailability is preferred. $(97,98)$ In particular, aminoglycosides do not have good intraocular bioavailability when given intravenously. (44) In specific situations, certain antibiotics should be preferred. For example, bacillus infections mandate the initial use of either vancomycin or clindamycin. (41) In cases of fungal sepsis and endophthalmitis amphotericin B provides good efficacy and broad coverage. $(99,100)$ It is fungostatic or fungocidal depending on concentration attained in body fluids. (101) It is an polyene antibiotic and it changes permeability of fungal 
cell membrane by binding to sterols, which causes fungal cell death as intracellular components leak out. (101) Treatment duration and total dose of intravenous drug are determined by the clinical response and the degree of systemic or non-ocular involvement. (102) Toxic side effects including renal and hepatic toxicity must be carefully monitored. (102) The penetration of amphotericin B into vitreous cavity is poor. (103) Doses of 5-10 microgram of intravitreal amphotericin is used for treatment. (103) However, retinal toxicities have also been reported in animal models at these doses. (103) The azole antibiotics are less toxic and have better ocular penetration. (104) Fluconazole and flucytosine have good intraocular penetration, but Candida species show high resitance to flucytosine. (104) Flucytosine can be used in combination with amphotericin B in cases of macular involvement and extensive inflammatory response. $(100,104)$ Itraconazole is useful in Aspergillus and Fusarium infections. (99) A new systemic voriconazole, when administered orally or intravenously, it has good intravitreal concentrations. (100) Intravitreal administration of voriconazole is also safe without evidence of retinal toxicity with concentrations up to $25 \mathrm{microgram} / \mathrm{ml}$. (105) The echinocandins (caspofungin, micafungin, and anidulafungin) are newer agents that exert their antifungal activity by binding D-glucan synthase, an enzyme involved in fungal cell wall synthesis. $(106,107)$ Because mammalian cells lack a cell wall, it also represents an ideal and specific target for antifungal therapy. (106) Echinocandins exert antifungal activity against Candida and Aspergillus species. $(106,107)$ However, they have limited penetration into the vitreous cavity so their role in the treatment of fungal endophthalmitis needs to be determined. (107)

\subsection{Intravitreal therapy}

Although the value of intravitreal antibiotics over and above the use of intravenous antibiotics has not been definitively established, most cases in our experience are of posterior diffuse disease and panophthalmitis which denote severe infection with extension of organisms into the vitreous. These cases should be treated aggressively as possible with both systemic and intravitreal antibiotics. In cases caused by bacteria, intravitreal injection of vancomycin $1 \mathrm{mg} / 0.1 \mathrm{ml}$ and ceftazidime $2 \mathrm{mg} / 0.1 \mathrm{ml}$ provides good coverage and avoids the toxicity associated with aminoglycosides. $(41,108)$ Repeated injections may be required since the half-life of these drugs in the vitreous cavity is short. (108) In most cases of fungal endophthalmitis, an intravitreal injection of 5-10 microgram amphotericin $B$ is recommended. (103) Using amphotericin B in this manner avoids its numerous systemic side effects, but its potential for retinal toxicity should be noted. (103) The use of intravitreal, topical and subtenon steroids should be avoided in fungal endophthalmitis. (99) However, the use of intravitreal steroid, dexamethasone in addition to intravitreal antibiotics is recommended for suppression of inflammatory mediators released in the vitreous in bacterial endophthalmitis. (108-111) The histopathological changes of the eyes treated with intravitreal vancomycin with dexamethasone $(0.4 \mathrm{mg} / \mathrm{ml})$ had less conjunctival inflammation, mild iridocyclitis, less vitreous cells, less choroidal vasculitis and retinitis compared to antibiotic treatment alone. $(109,110)$

Topical steroids are also used in patients with anterior focal or diffuse endophthalmitis to reduce the number of inflammatory cells in the anterior chamber, thereby preventing the complications such as formation of synechiae and secondary glaucoma. (112-114) 
Topical antibiotics are definitively indicated if keratitis develops and adjunctive therapy includes the use of cycloplegics, ocular hypotensives and topical steroids. $(113,114)$

\subsection{Surgical treatment}

The timing of and necessity for vitrectomy remains unclear in endogenous endophthalmitis. $(115,116)$ The benefits of vitreous tap outweigh the benefits of vitrectomy for anterior focal or diffuse and posterior focal cases with endogenous endophthalmitis. (38) In general vitrectomy is indicated in cases of posterior diffuse cases with prominent vitreous involvement, and also for cases showing progressive disease despite intensive medical therapy. (116) In these cases small gauge vitrectomy is effective in clearing the vitreous from the inflammatory debris, cells and mediators. (117) Other advantage includes the possibility to have larger sample to make the diagnosis and also to deliver a therapeutic level of drug in the vitreous. $(118,119)$ In these cases vitrectomy and intravitreal antibiotics may, however, prevent ocular atrophy or the necessity for enucleation. (119)

\section{Prognosis}

The visual outcome is usually good in the anterior form of endophthalmitis, differently from posterior diffuse and panophthalmitis forms. (19) The outcome of posterior diffuse endophthalmitis or panophthalmitis is frequently blindness, regardless of the treatment measures. (19) In a recent study surveying cases in Singapore over a 4-year period, 17 of 32 affected eyes ended up with no light perception. (4) In only $40 \%$ of patients with endogenous endophthalmitis vision is preserved with ability to count fingers or better. (4)

The virulence factor of the organism and age of the patient are important factors predicting outcome. $(4,5)$ Other variables resulting in poorer outcome include severity of underlying systemic illness, misdiagnosis or delay in diagnosis, and inappropriate, inadequate or delayed treatment, low intraocular pressure, initial visual acuity of light perception, severe hypopyon and absent red reflex. $(5,6)$ Ultrasonography negative prognostic factors are vitreous and subhyaloid opacities, choroidal and retinal detachments. (35) In general Grampositive infections involving microbes such as Staphylococcus and Streptococcus species result in a better outcome. $(112,120)$ However, Bacillus infections are typically rapidly progressive with a poorer prognosis. (120) Gram-negative organisms, including Klebsiella pneumonia, E. coli, P aeruginosa, often result in severe infection and a very poor prognosis. $(6,12)$ Exceptions include Haemophilus and Neisseria, but these are uncommon causes of endogenous endophthalmitis. $(121,122)$ Fungal endogenous endophthalmitis usually result in very poor outcomes, but those caused by Candida species can often be treated effectively if early and appropriate antifungals are used. $(98,99)$

\section{Conclusion}

Endogenous endophthalmitis continues to occur among the patients with infective endocarditis despite the continuing development of effective antibiotics. Although it is devastating, vision can sometimes be salvaged, especially if diagnosis is made early and prompt systemic therapy instituted. The role of intravitreal antibiotics and vitrectomy is not well defined but they have a definite role in cases which progress despite medical therapy and also where fungi are implicated. Future challenge ahead include the aging population 
and the development of new microbial antibiotic resistance. A coordinated multidisciplinary effort will be required to keep abreast of this difficult condition.

\section{References}

[1] Lopez J, Revilla A, Vilacosta I, et al. Multiple-valve infective endocarditis: Clinical, microbiologic, echocardiographic and prognostic profile. Medicine (Baltimore) 2011 Jun 18 (Epub ahead of print)

[2] Silverman ME, Upshaw CB Jr. Extra-cardiac manifestations of infective endocarditis and their historical descriptions. Am J Cardiol 2007;100:1802-7.

[3] Walpot J, Klazen C, blok W, et al. Embolic events in infective endocarditis: a review and report of 4 cases. Acta Clin Belg 2005;60:139-45.

[4] Ming PY, Phaik CS. Endogenous endophthalmitis SGH Proceedings 2004;13:113-20.

[5] Okada AA, Johnson RP, Liles WC, et al. Endogenous bacterial endophthalmitis: report of a ten-year prospective study. Ophthalmology 1994;101:832-8.

[6] Wong JS, Chan TK, Lee HM, et al. Endogenous bacterial endophthalmitis: an East Asian experience and a reappraisal of a severe ocular affliction. Ophthalmology 2000;107:1483-91.

[7] Lee SY, Chee SP. Group B Streptococcus endogenous endophthalmitis. Case reports and review of the literature. Ophthalmology 2002;109:1879-86.

[8] Chee SP, Ang CL. Endogenous Klebsiella endophthalmitis- a case series. Ann Acad Med Singapore 1995;24:473-8.

[9] Jain ML, Garg AK. Metastatic endophthalmitis in a patient with major burns: a rare complication. Burns 1995;21:72-3.

[10] Banerjee SN, Emori TG, Culver DH, et al. Secular trends in nosocomial primary bloodstream infections in the United States, 1980-1989. National Nosocomial Infections Surveillance System. Am J Med 1991;91:86S-89S.

[11] Chee SP, Jap A. Endogenous endophthalmitis. Current Opinion in Ophthalmology 2001;12:464-70.

[12] Yang CS, Tsai HY, Sung CS, et al. Endogenous Klebsielle endophthalmitis associated with pyogenic liver abscess. Ophthalmology 2007;114:876-80.

[13] Kiwan YA, Hayat N, Vijayaraghavan DG, et al. Infective endocarditis: A prospective study of 60 consecutive cases. Mater Med Pol 1990;22:173-5.

[14] Al-Tawfiq JA, Sufi I. Infective endocarditis at a hospital in Saudi Arabia: epidemiology, bacterial pathogens and outcome. Ann Saudi Med 2009; 29:433-6.

[15] Binder MI, Chua J, Kaiser PK, et al. Endogenous endophthalmitis. An 18-year review of culture-positive cases at a tertiary care center. Medicine (Baltimore) 2003;82:97-105.

[16] Durand ML. Bacterial endophthalmitis. Curr Infect Dis Rep 2009;11:283-8.

[17] Schiedler V, Scott IU, Flynn HW Jr, et al. Culture-proven endogenous endophthalmitis: clinical features and visual acuity outcomes. Am J Ophthalmol 2004;137:725-31.

[18] Ness T, Serr A. Diagnostics for endophthalmitis. Klin Monbl Augenheilkd 2008;225:449.

[19] Liang L, Lin X, Yu A, et al. The clinical analysis of endogenous endophtahlmitis. Yan Ke Xue Bao 2004,20:144-8.

[20] Greenwald MJ, Wohl LG, Sell H. Metastatic bacterial endophthalmitis: a contemporary reappraisal. Surv Ophthalmol 1986;31:81-101. 
[21] Puliafito CA, Baker AS, Foster CS. Infectious endophthalmitis. Ophthalmology 1982;89:921-9.

[22] Pflugfelder CS, Flynn HW Jr. Infectious endophthalmitis. Infect Dis Clin North Am 1992;6:859-73.

[23] Davis JL, Nussenblat RB, Bachman DM, et al. Endogenous bacterial retinitis in AIDS. Am J Ophthalmol 1989;107:613-23.

[24] Margo CE, Mames RN, Guy JR. Endogenous Klebsiella endophthalmitis. Report of two cases and review of the literature. Ophthalmology 1994;101:1298-301.

[25] Tseng CY, Liu PY, Shi ZY, et al. Endogenous endophthalmitis due to Escherichia coli:case report and review. Clin Infect Dis 1996;22:1107-8.

[26] Jeng BH, Kaiser BK, Lowder CY. Retinal vasculitis and posterior pole "hypopyons" as early signs of acute bacterial endophthalmitis. Am J Ophthalmol 2001;131:800-2.

[27] Magadur-Joly G, Raffi F, Bouchut P, et al. Hematogenic bacterial endophthalmitis. A rare infection with very poor functional prognosis. Ann Med Interne (Paris) 1996;147:212-7.

[28] Molina DN, Colon M, Bermudez RH, et al. Unusual presentation of Pseudomonas aeruginosa infections: a review. Bol Asoc Med P R 1991;83:160-3.

[29] Treister G, Rothoff L, Yalon M, et al. Bilateral blindeness fron panophthalmitis in a case of bacterial endocarditis. Ann Ophthalmol 1982;14:663-4.

[30] Khan A, Okhravi N, Lightman S. The eye in systemic sepsis. Clin Med 2002;2.444-8.

[31] Ness T, Pelz K, Hansen LL. Endogenous endophtahlmitis: microorganisms, disposition and prognosis. Acta Ophthalmol Scand 2007;85:852-6.

[32] Hori J, Vega JL, Masli S. Review of ocular immune privilege in the year 2010: modifying the immune privilege of the eye. Ocul Immunol Inflamm 2010;18:325-33.

[33] Novosad BD, Callegan MC. Severe bacterial endophthalmitis: towards improving clinical outcomes. Expert Rev Ophthalmol 2010;5:689-98.

[34] Bartz-Schmidt KU, Bermig J, Kirchoff B, et al. Prognostic factors associated with the visual outcome after vitrectomy for endophthalmitis. Graefes Arch Clin Exp Ophthalmol 1996;234:S51-8.

[35] Uchio E, Ohno S. Ocular manifestations of systemic infections. Curr Opin Ophtahlmol 1999;10:452-7.

[36] Riss JM, Righini-Chossegros M, Paulo F, et al. Endogenous bacterial endophthalmitis. Report of three cases. J Fr Ophthalmol 1990;13:327-31.

[37] Hutnik CM, Nicolle DA, Munoz DG. Orbital aspergillosis. A fatal masquerader. J Neuroophthalmol 1997;17:257-61.

[38] Ho V, Ho LY, Ranchod TM, et al. Endogenous methicillin-resistant Staphylococcus aureus endophthalmitis. Retina 2011;31:596-601.

[39] Saffra NA, Desai RU, Seidmann CJ, et al. Endogenous fungal endophthalmitis after cardiac surgery. Ophthalmic Surg Lasers Imaging 2010;28:e1-3.

[40] Willermain F, Bradstreet C, Kampauridis S, et al. different presentations of ophthalmic aspergillosis. Eur J Ophthalmol 2008;18:827-30.

[41] Miller JJ, Scott IU, Flynn HW Jr, et al. Endophthalmitis caused by Bacillus species. Am J Ophthalmol 2008;145:883-8.

[42] al Hazzaa SA, Tabbara KF, Gammon JA. Pink hypopyon: a sign of Serratia marcescens endophthalmitis. Br J Ophthalmol 1992;76:764-5.

[43] Equi RA, Green WR. Endogenous Serratia marcescens endophthalmitis with dark hypopyon: case report and review. Surv Ophthalmol 2001;46:259-68. 
[44] Ang LP, Lee HM, Au Eong KG, et al. Endogenous Klebsiella Endophthalmitis. Eye (Lond) 2000;14:855-60.

[45] Hauch A, Elliott D, Rao NA, et al. Dark hypopyon in Streptococcus bovis endogenous endophthalmitis: clinicopathological correlations. J Ophthalmic Inflamm Infect 2010;30:39-41.

[46] Hawkins AS, Deutsch TA. Infectious endophthalmitis. Curr Infect Dis Rep 1999;1:17277.

[47] Bogadhi B. Fungal endogenous endophthalmitis. J Fr Ophthalmol 2011;34:40-45

[48] Kaburaki T, Takamoto M, Araki F, et al. Endogenous Candida albicans infection causing subretinal abscess. Int Ophthalmol 2010;30:203-6.

[49] Rana M, Fahad B, Abid Q. Embolic aspergillus endophthalmitis in an immunocompetent patient from aortic root aspergillus endocarditis. Mycoses 2008;51:352-3.

[50] Chung KS, Kim YK, Song YG, et al. Clinical review of endogenous endophthalmitis in Korea: a 14-year review of culture positive cases of two large hospitals. Yonsei Med J 2011,1:630-4.

[51] Hueber A, Welsandt G, Grajewski RS, et al. Fulminant endogenous anterior uveitis due to Listeria monocytogenes. Case Report Ophthalmol 2010;27:63-5.

[52] Cornut PL, Chiquet C. Endogenous bacterial endophthalmitis. J Fr Ophthlmol 2011;34:51-7.

[53] Arcieri ES, Jorge EF, de Abrea Ferreira L, et al. Bilateral endogenous endophthalmitis associated with infective endocarditis: case report. Braz J Infect Dis 2001;5:356-9.

[54] Nagelberg HP, Petashnick DE, To KW, et al. Group B streptococcal metastatic endophthalmitis. Am J Ophthalmol 1994;117:498-500.

[55] Wann SR, Liu YC, Yen MY, et al. Endogenous Escherichia coli endophthalmitis. J Formos Med Assoc 1996;95:56-60.

[56] Park SB, Searl SS, Aquavella JV, et al. Endogenous endophthalmitis caused by Escherichia coli. Ann Ophthalmol 1993;25:95-9.

[57] Durante-Mangoni E, Tripodi MF, Albisinni R, et al. Management of Gram-negative and fungal endocarditis. International Journal of Antimicrobial Agents 2010;36:S40-S45.

[58] Faraawi R, Fong IW. Escherichia coli emphysematous endophthalmitis and pyelonephritis. Case report and review of the literature. Am J Med 1988;84:636-9.

[59] Tseng CY, Yuk-Fong Liu P, Shi ZY, et al. Endogenous endophthalmitis due to Escherichia coli: Case report and Review. Clinical infectious Diseases 1996;22:11078.

[60] Lauridsen TK, Arpi M, Fritz-Hansen T, et al. Infectious endocarditis caused by Escherichia coli. Scand J Infect Dis 2011;43:545-6.

[61] Chen YJ, Kuo HK, Wu PC, et al. A 10-year comparison of endogenous endophthalmitis outcomes: an east Asian experience with Klebsiella pneumniae infection. Retina 2004;24:383-90.

[62] Kashani AH, Eliott D. Bilateral Klebsieela pneumoniae ( $\mathrm{k} 1$ serotype) endogenous endophthalmitis as the presenting sign of disseminated infection. Ophthalmic Surg Lasers Imaging 2011;10:e12-4.

[63] Ramonas KM, Freilich BD. Iris abscess as an unusual presentation of endogenous endophthalmitis in a patient with bacterial endocarditis. Am J Ophthalmol 2003;135:228-9. 
[64] Seles S, Lang GE. Ocular manifestations of an infectious endocarditis. Klin Monbl Augenheilkd 2007;224:606-8.

[65] McCue JD, Dreher RJ. Bilateral endophthalmitis with Streptococcus viridans endocarditis. J Maine med Assoc. 1979;70:463-5.

[66] Kobayashi K, Fujiseki Y, Takahashi K, et al. Bacterial endophthalmitis caused by B streptococcus endocarditis. Nippon Ganka Gakkai Zasshi 2006;110:199-204.

[67] Chihara S, Siccion E. Group B streptococcus endophthalmitis with endocarditis. Mayo Clin Proc 2005;80:74.

[68] Pokharel D, Doan AP, Lee AG. Group B streptococcus endogenous endophthalmitis presenting as septic arthritis and a homonymous hemianopsia due to embolic stroke. Am J Ophthalmol 2004;138:300-2.

[69] Hui M. Streptococcusanginosus bacteremia: Sutton's law. J Clin Microbiol 2005;43:6217.

[70] Hadid OH, Shah SP, Sherafat H, et al. Streptococcus anginosus-associated endogenous endophthalmitis mimicking fungal endophthalmitis. J Clin Microbiol 2005;43:42756.

[71] Dreier J, Vollmer T, Freytag CC, et al. Culture-negative infectious endocarditis caused by Bartonella spp.: 2 case reports and a review of the literature. Diagn Microbiol Infect Dis 2008;61:476-83.

[72] Puechal X. Whipple's disease. Rev Med Interne 2009;30:233-41.

[73] Edouard S, Raoult D. Bartonella henselae, an ubiquitous agent of proteiform zoonotic disease. Med Mal Infect 2010;40:319-30.

[74] Escher R, Roth S, Droz S, et al. Endocarditis due to Tropheryma whipplei: rapid detection, limited genetic diversity, and long-term clinical outcome in a local experience. Clin Microbiol Infect 2010;16:1213-22.

[75] Falcone M, Barzaghi N, Carosi G, et al. Candida infective endocarditis: report of 15 cases from a prospective multicenter study. Medicine (Baltimore) 200988:160-8.

[76] Rao NA, Hidayat A. a comparative clinicopathologic study of endogenous mycotic endophthalmitis: variations in clinical and histological changes in candidiasis compared to aspergillosis. Trans Am Ophthalmol Soc 2000;98:183-93.

[77] Brooks RG. Prospective study of Candida endophthalmitis in hospitalized patients with candidemia. Arch Inter Med 1989;149:226-8.

[78] Weishaar PD, Flynn HW Jr, Murray TG, et al. Endogenous aspergillus endophthalmitis: Clinical features and treatment outcomes. Ophthalmology 1998;105:57-65.

[79] Sheu SJ, Chen YC, Kuo NW, et al. Endogenous cryptococcal endophthalmitis. Ophthalmology 1998;105:377-81.

[80] Crump JR, Elner SG, Elner VM, et al. Cryptococcal endophthalmitis: case report and review. Clin Infect Dis 1992;14:1069-73.

[81] Blumenkranz MS, Stevens DA. Endogenous coccidioidal endophthalmitis. Ophthalmology 1980;87;974-84.

[82] Weingeist TA, Watzke RC. Ocular involvement by histoplasma capsulatum. Int Ophthalmol Clin 1983;23:33-47.

[83] Leung C, Farmer JP, Zoutman DE, et al. Histoplasma capsulatum endophthalmitis in southeastern Ontario. Can J Ophthalmol 2010;45:90-1.

[84] Louie T, el Baba F, Shulman M, et al. Endogenous endophthalmitis due to Fusarium: case report and review. Clin Infect Dis 1994;18:585-8.

[85] McGuire TW, Bullock JD, Bullock JD Jr, et al. Fungal endophthalmitis. An experimental study with a review of 17 human ocular cases. Arch Ophthalmol 1991;109:1289-96. 
[86] Kalkancı A, Ozdek S. Ocular fungal Infections. Curr Eye Res 2011;36:179-89.

[87] Vasseneix C, Bodaghi B, Muraine M, et al. Intraocular fluids analysis for etiologic diagnosis of presumed infectious uveitis. J Fr Ophthalmol 2006;29:398-403.

[88] Harper TW, Miller D, Schiffman JC, et al. Polymerase chain reaction analysis of aqueous and vitreous specimens in the diagnosis of posterior segment infectious uveitis. Am J Ophthalmol 2009;147:140-7.

[89] Odds FC, Bernaerts R. Chromagar candida, a new differential isolation medium for presumptive isolation of clinically important candida species. Journal of Clinical Microbiology 1994;32:1923-9.

[90] Piao YS, Liu HG, Liu XJ. Significance of MUC5B antibody in differential diagnosis between Aspergillus species and Mucorales of fungal sinusitis. Zhonghua Bing Li Xue Za Zhi 2008;37:255-8.

[91] Shashikala, Kanungo R, Srinivasan S, et al. Unusual morphological forms of Cryptococcus neoformans in cerebrospinal fluid. Indian J Med Microbiol 2004;22:188-90.

[92] Sarosi GA, Lawrence JP, Smith DK, et al. Rapid diagnostic evaluation of bronchial washings in patients with suspected coccidioidomycosis. Semin Respir Infect 2001;16:238-41.

[93] Turno-Krecicka A, Misiuk-Hojlo M, Grzybowski A, et al. Early vitrectomy and diagnostic testing in severe infectious posterior uveitis and endophthalmitis. Med Sci Monit 2010;16:296-300.

[94] Heidemann DG, Trese M, Murphy SF, et al. Endogenous Listeria monocytogenes endophthalmitis presenting as keratouveitis. Cornea 1990;9:179-80.

[95] Connell PP, O’Neill EC, Fabiyni D, et al. Endogenous endophthalmitis: 10-year experience at a tertiary referral center. Eye (Lond) 2011;25:66-72.

[96] Torii H, Miyata H, Sugisaka E, et al. Bilateral endophthalmitis in a patient with bacterial meningitis caused by Streptococcus pneumonia. Ophthalmologica 2008;222:357-9.

[97] Ang M, Jap A, Chee SP. Prognostic factors and outcomes in endogenous Klebsiella pneumonia endophthalmitis. Am J Ophthalmol 2011;151:338-44.

[98] Connell PP, O'Neill EC, Amirul Islam FM, et al. Endogenous endophthalmitis associated with intravenous drug abuse: seven-year experience at a tertiary referral center. Retina 2010;30:1721-5.

[99] Chakrabarti A, Shivaprakash MR, Singh R, et al. Fungal endophthalmitis: Fourteen years' experience from a center in India. Retina 2008;28:1400-7.

[100] Riddell J $4^{\text {th }}$, Corner GM, Kaufmann CA. Treatment of endogenous fungal endophthalmitis: focus on new antifungal agents. Clin Infect Dis 2011;52:648-53.

[101] Goldblum D, Rohrer K, Frueh BE, et al. Ocular distribution of intravenously administered lipid formulations of amphotericin B in a rabbit model. Antimic Agents Chemother 2002;46:3719-23.

[102] Narendran N, Balasubramaniam B, Johnson E, et al. Five-year retrospective review of guideline-based management of fungal endophthalmitis. Acta Ophthalmol 2008;86:525-32.

[103] Payne JF, Keenum DG, Sternberg P Jr, et al. Concentrated intravitreal amphotericin B in fungal endophthalmitis. Arch Ophthalmol 2010;128;1546-50.

[104] Annamalai T, Fong KC, Choo MM. Intravenous fluconazole for bilateral endogenous Candida endophthalmitis. J Ocul Phramacol Ther 2011;27:105-7. 
[105] Funakoshi Y, Yakushijin K, Matsuoka H, et al. Fungal endophthalmitis successfully treated with intravitreal voriconazole injection. Intern Med 2011;50:941.

[106] Mora-Duarte J, Betts R, Rotstein C, et al. Comparision of capsofungin and amphotericin B for invasive candidiasis. N Eng J Med 2002;347:2020-9.

[107] Gauthier GM, Nork TM, Prince R, et al. Subtheurapeutic ocular penetration of capsofungin and associated treatment failure in candida albicans endophthalmitis. Clin Inf Dis 2005;41:27-8.

[108] Mehta S, Armstrong BK, Kim SJ et al. Long-term potency, sterility and stability of vancomycin, ceftazidime and moxifloxacin for treatment of bacterial endophthalmitis. Retina 2011;Feb 23 (Epub ahead of print)

[109] Albrecht E, Richards JC, Polock T, et al. Adjunctive use of intravitreal dexamethasone in presumed bacterial endophthalmitis: a randomised trial. $\mathrm{Br} \mathrm{J}$ Ophthalmol 2011;Feb 2 (Epub ahead of print)

[110] Liu F, Kwok AK, Cheung BM. The efficacy of intravitreal vancomycin and dexamethasone in the treatment of experimental bacillus cereus endophtahlmitis. Curr Eye Res 2008;33:761-8.

[111] Ermis SS, Cetinkaya Z, K1yıc1 H, et al. Effects of intravitreal moxifloxacin and dexamethasone in experimental Staphylococcus endophthalmitis. Curr Eye Res 2007;32:337-44.

[112] Nentwich MM, Kampik A, de Kaspar HM. Chronic endogenous endophthalmitis. Klin Monbl Augenheilkd 2008;225:929-33.

[113] Pavesio CE, Decory HH. Treatment of ocular inflammatory conditions with loteprednol etabonate. Br J Ophthalmol 2008;92:455-9.

[114] Smith A, Pennefather PM, Kaye SB, et al. Fluoroquinolones: place in ocular therapy. Drugs 2001;61:747-61.

[115] Laube T, Akgül H, Brockmann C, et al. Endogenous bacterial endophthalmitis: a retrospective study in 22 consecutive cases. Klin Monbl Augenheilkd 2004;221:1018.

[116] Maguire JL. Postoperative endophthalmitis: optimal management and the role and timing of vitrectomy surgery. Eye (London) 2008;22:1290-300.

[117] Thompson JT. Advantages and limitations of small gauge vitrectomy. Surv Ophthalmol 2011;56:162-72.

[118] Wen X, Zhong K, Wang Z, et al. Vitrectomy combined with intravitreal injection of drugs for the management of advanced suppurative endophthalmitis. Yan Ke Xue Bao 1992;8:164-8.

[119] Yarng SS, Hsieh CC, Chen TL. Vitrectomy for endogenous Klebsiella pneumonia endophthalmitis with massive subretinal abscess. Ophthalmic Surg Lasers 1997; 128:147-50.

[120] Vahey JB, Flynn HW Jr. Results in the management of Bacillus endophthalmitis. 1991;22:681-6.

[121] Sullivan P, Clark WL, Kaiser PK. Bilateral endogenous endophthalmitis caused by HACEK microorganism. Am J Ophthalmol 2002;133:144-5.

[122] Balaskas K, Potamitou D. Endogenous endophthalmitis secondary to bacterial meningitis from Neissereia meningitides: a case report and review of the literature. Cases J 2009;2:149. 


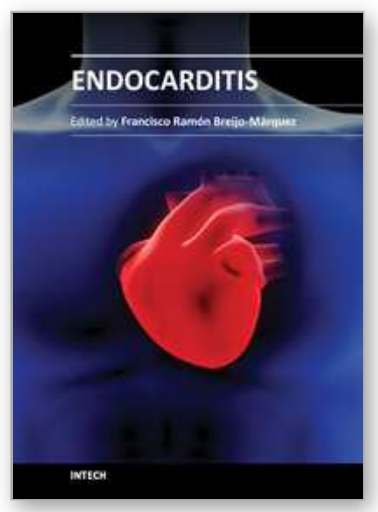

\author{
Endocarditis \\ Edited by Prof. Francisco Ramón Breijo-Márquez
}

ISBN 978-953-307-901-1

Hard cover, 152 pages

Publisher InTech

Published online 20, January, 2012

Published in print edition January, 2012

Endocarditis is a disease that occurs as a result of the inflammation of the endocardium. It is an inflammatory process located in the inner lining of the cardiac chambers and native or prosthetic valves. It is characterized by colonization or invasion of the heart valve vegetations composed of platelets forming, fibrin and microcolonies of microorganisms, and occasionally of inflammatory cells. Other structures may also be affected, such as the interventricular septum, chordae tendineae, the mural endocardium or even intra-cardiac implants. The book covers, with scientific rigour, the most prevalent causes and current treatments of endocarditis, as well as the cases when the organs remote from the heart are affected by this disease.

\title{
How to reference
}

In order to correctly reference this scholarly work, feel free to copy and paste the following:

Ozlem Sahin (2012). Ocular Complications of Endocarditis, Endocarditis, Prof. Francisco Ramón BreijoMárquez (Ed.), ISBN: 978-953-307-901-1, InTech, Available from:

http://www.intechopen.com/books/endocarditis/ocular-complications-of-endocarditis

\section{INTECH}

open science | open minds

\section{InTech Europe}

University Campus STeP Ri

Slavka Krautzeka 83/A

51000 Rijeka, Croatia

Phone: +385 (51) 770447

Fax: +385 (51) 686166

www.intechopen.com

\section{InTech China}

Unit 405, Office Block, Hotel Equatorial Shanghai

No.65, Yan An Road (West), Shanghai, 200040, China

中国上海市延安西路65号上海国际贵都大饭店办公楼 405 单元

Phone: +86-21-62489820

Fax: +86-21-62489821 
(C) 2012 The Author(s). Licensee IntechOpen. This is an open access article distributed under the terms of the Creative Commons Attribution 3.0 License, which permits unrestricted use, distribution, and reproduction in any medium, provided the original work is properly cited. 